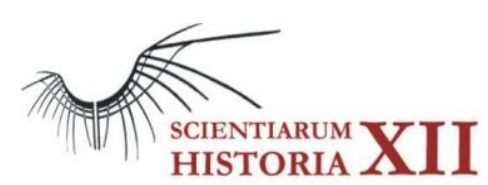

Marianne North lives em Virginia Woolf

\title{
Marianne North vive in Virginia Woolf
}

\author{
Renata Cesar de Oliveira ${ }^{1}$ \\ Laboratório de Métodos Avançados e Epistemologia, Instituto Tércio Pacitti de Aplicações \\ e Pesquisas Computacionais, Universidade Federal do Rio de Janeiro, Programa de Pós- \\ graduação em História das Ciências e das Técnicas e Epistemologia, \\ Universidade Federal do Rio de Janeiro \\ renatacesarouff@gmail.com / renatacesaro@ufrj.br
}

Recebido: 4/12/2019 Aceito: 8/12/2019 Publicado: 13/12/2019

\begin{abstract}
This article points to the influence of Marianne North's nineteenth-century work (1830 - 1890) on Virginia Woolf's (1882-1941) literary writing. North's narrative in both her travel diaries and over 800 botanical landscape oil paintings, housed at the Royal Kew Gardens (London, England), inspired descriptions of nature and color, aspects of interdependence and evolutionism, especially in Virginia Woolf's short stories, romances and essays. "Kew Gardens" is an example of a tale, in which the garden is scenery and character, thus questioning anthropocentrism, social rules and the complexity of human and nature. North and Woolf represent the transition between the nineteenth and twentieth centuries, pointing to aspects of modernism and the role of women in the world, whether in science or the arts.
\end{abstract}

Keywords: Marianne North. Virginia Woolf. Kew Gardens. Artsci.

Resumo. Este artigo aponta a influência da obra oitocentista de Marianne North (1830 1890) na escrita literária de Virginia Woolf (1882-1941). A narrativa de North tanto em seus diários de viagens quanto nas mais de 800 pinturas a óleo acerca de paisagens botânicas, abrigadas no Royal Kew Gardens (Londres, Inglaterra), inspiraram as descrições da natureza e da cor, aspectos de interdependência e evolucionismo, principalmente nos contos, romances e ensaios de Virginia Woolf. "Kew Gardens" é um exemplo de conto, no qual o jardim é cenário e personagem, questionando assim o antropocentrismo, as regras sociais e a complexidade humana e da natureza. North e Woolf

\footnotetext{
${ }^{1}$ Doutoranda no Programa de Pós-Graduação em História das Ciências, das Técnicas e Epistemologia HCTE, NCE, UFRJ.
} 
representam a transição entre o século XIX e o XX, apontando aspectos do modernismo e do papel da mulher no mundo, seja nas Ciências ou nas Artes.

Palavras-chave: Marianne North. Virginia Woolf. Kew Gardens. Artsci.

\section{Introdução}

Este artigo aborda a importância de um dado estudo do passado para a contemporaneidade, ou seja, é possível atualizações da pesquisa? Sem cair no utilitarismo, ${ }^{2}$ de que só se deve estudar aquilo que se mostra útil no presente, o que é uma falácia, buscamos desdobramentos da obra de Marianne North (1830-1890) tanto temporais, nos séculos XX e XXI, quanto nos espaços que interconectam arte e ciência, sujeito e obra. Aqui, priorizamos os desdobramentos no século XX, uma vez que a pesquisa para o século XXI ainda está em curso, qual seja, a identificação das espécies retratadas por North no Brasil e a verificação no Livro Vermelho da Flora do Brasil (MARTINELLI; MORAES, 2014) daquelas extintas ou em perigo de extinção, ou seja, uma atualização para a História da Botânica Tropical.

Uma das contribuições de Marianne North, no século XX, é a relação com a literatura de Virginia Woolf. Esta associação foi possível quando da leitura do conto Kew Gardens, lançado pela autora em 1919, e, posteriormente, por meio de pesquisa e acesso ao artigo acadêmico, apresentado na conferência anual sobre Virginia Woolf, em 2008, por especialistas e editores da obra desta escritora, qual seja, The Botanical Works of Marianne North (painter, writer, traveler), edited by absortion into Virginia Woolf's writting (HALLER, 2008).

O objetivo deste artigo é reforçar a proposta de Evelyn Haller (2008) acerca da assimilação da contribuição de North por Woolf, numa visão de interface arte/ciência. A busca por bases comuns a conceitos aparentemente distintos nos diferentes campos disciplinares ou empregados por diferentes autores em campos correlatos poderá ser reveladora dos operadores epistêmicos fundantes que norteiam o endereçamento de valores do conhecimento que atravessam o tempo.

Pesquisas no campo da Neurociência vêm provendo evidências que acabam por inspirar uma nova concepção do fazer científico, entendendo-o também como uma experiência estética, seja no laboratório ou no campo. Proposto por Fróes (2010, 2015), o método Artsci revisita a tensão histórica razão-emoção, sujeito-objeto, propondo que estes esquemas dualistas sejam vencidos nos laboratórios e centros de ciência. Segundo Fróes (2015, 2016), o dualismo cartesiano instalou-se nas ciências como uma cultura da mente sem corpo: "penso, logo existo" (DESCARTES, 2007). À arte cabe preservar a unidade mente corpo, agregando valores subjetivos à obra. Fróes propõe a existência de dois vetores de força impulsionando a prática científica: o primeiro, alimentaria aspectos pré-formais da experimentação, enraizantes, sensíveis, com qualidades ditas subjetivas reconhecidas no processo de criação em arte. Um segundo vetor fortaleceria a capacidade de abstração e análise, e ampliaria

\footnotetext{
2 Para se aprofundar no tema, ver ORDINE, Nuccio. A utilidade do inútil: um manifesto. Rio de Janeiro: Zahar, 2013.
} 


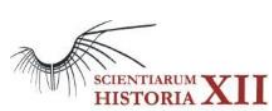

caminhos de significação com foco no objeto; estes, também de inegável relevância no campo da arte, compreendem a essência da narrativa científica, sobretudo do método em Descartes, que defende a depuração das influências do primeiro vetor (FRÓES, 2016). Fróes defende que a criação científica se assenta, inescapavelmente, na associação destes dois vetores como base operacional do tripé funcional das experiências conscientes - cognição, afeto e estética. A afirmação científica se situa à meia distância entre o sujeito e o objeto. $\mathrm{O}$ objeto, segundo Fróes, ainda que não alcançável em sua essência primordial, dada a clausura cognitiva/perceptual inerente à condição humana, é mais eficientemente perscrutável se superados os impositivos do dualismo cartesiano. A arte seria um disparador de ambos os sistemas de força (FRÓES, 2015, 2016). Propostas como essa favorecem a confiança no entrecruzamento destas raízes epistemológicas reconhecidas no processo de construção do conhecimento na arte e na ciência, favorecendo novos olhares que nos abram para uma recontextualização e redimensionamento da experiência do fazer científico, aproximando-os da inteireza da condição humana, ao passo que nos permitem reformular o olhar que lançamos ao passado de construção de nossos campos de conhecimento, levando-nos a redimensionar também os sujeitos, de corpo e espírito, na ciência, com efeitos previsíveis para um presente que se pretende transformador.

Marianne North, a protagonista desta pesquisa, é um exemplo icônico desta inteireza humana na construção de conhecimento. Marianne nos possibilita estudar profundamente lugares de encontro de diferentes campos de conhecimento, borrando suas bordas, e enriquecendo-as de significados. Marianne pintou mais de 800 telas a óleo, a maioria de paisagens botânicas, contudo, não foi considerada formalmente artista pelas academias ou escolas de arte; fez ciência (criou um acervo de exsicatas, realizou comunicação entre museus e centros de ciências, descobriu novas espécies, entre outros) e não foi vista como cientista; era mulher e se recusava a ocupar o lugar imposto às mulheres, no século XIX, pelo vitorianismo inglês. Portanto, há terreno fértil para estudo das fronteiras e bordas, dos lugares e das veladuras.

\section{Marianne North (1830-1890) e Virginia Woolf (1882-1941)}

A inglesa Marianne North nasceu em Hastings e faleceu em Alderley, em função de complicações do fígado e de diversas enfermidades, as quais adquiriu nas inúmeras viagens. Filha do meio de uma família da aristocracia inglesa, estudou poucos anos em colégio para moças, não se adaptando aos costumes vitorianos. Para ela, o matrimônio era uma instituição que levava "a uma experiência terrível, na qual a mulher era transformada numa espécie de criada eminente" (NORTH, 1892, p. 11); portanto, sua formação foi no seio familiar e, sobretudo, por meio das viagens com o pai, membro do parlamento pelo Partido Liberal e apaixonado por botânica. Prometeu à mãe no leito de morte, em 1855, não se casar para acompanhar o pai, com quem tinha grande afinidade (Idem, ibidem, p. 30).

O falecimento do pai, em 1869, foi um divisor de águas na vida de Marianne North. A partir daí, aos 40 anos, de posse da herança, iniciou suas grandes viagens: duas de circumnavegação, atravessando oito vezes o Oceano Atlântico e duas vezes ao Índico e ao Pacífico. Visitou os Estados Unidos, Chile, Brasil, Canadá, Índia, Jamaica, Japão, Java, Singapura, África do Sul, Tenerife, Ilhas Seichelles, Tasmânia, Sri Lanka, Java, Bornéu (Sarawak), Havaí, Austrália e Nova Zelândia (BANDEIRA, 2012, p. 154). Viajava desacompanhada, utilizando uma rede de relacionamento pessoal, da qual faziam parte cientistas, diretores de instituições, artistas, membros da realeza, da marinha inglesa e de camadas abastadas da 


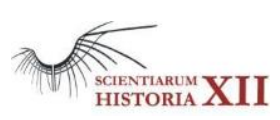

sociedade inglesa para indicações, como cartas de recomendação e contatos nas cidades para onde viajaria; assim, contava com apoio local de ingleses, tradutores para o idioma, entre outros. Segundo Bandeira (2012), Marianne tinha a capacidade de comunicação para circular com grande independência pelas diversas camadas sociais nos locais pelos quais viajava.

Marianne North descobriu um novo gênero e quatro novas espécies de plantas, nenhuma no Brasil, as quais foram batizadas em homenagem póstuma por meio de identificação em suas pinturas, realizada por Joseph Hooker, a saber: a) Northea seychellana - uma árvore das ilhas Seychelles; b) Nepenthes northiana - a maior das plantas insetívoras de Bornéu; c) Crinum northiana - uma das Amarílis; d) Areca northeana - palmeira do gênero Plumerian e) Kniphofia northiana - da família das lilácias africanas (BANDEIRA, 2012). No Dictionary of National Biography, ${ }^{3}$ Leslie Stephen escreveu, no verbete para Marianne North, que esta teria descoberto novas espécies, quatro das quais fez conhecidas pela primeira vez na Europa, e comenta que estas novas espécies receberam seus nomes em homenagem à descobridora, mas não os cita, num claro apagamento do nome e da importância da autora.

Sobre as exposições, a primeira foi realizada, em 1877, numa galeria em Mayfair (Londres, Inglaterra), tendo atraído as visitas do imperador D. Pedro II (1825-1891) e da imperatriz Teresa Cristina (1822-1889), interessados em ver suas pinturas. Posteriormente, foi convidada para emprestar suas 500 obras para exposição no Museu de História Natural, em Kensington (Londres, Inglaterra), para a qual foi organizado um primeiro catálogo (BANDEIRA, 2012). Em 1882, Marianne North elaborou um projeto museográfico e doou as 627 obras uma galeria no Royal Kew Gardens. O prédio foi restaurado por James Fergusson (1808 - 1886) - amigo de North, historiador da arquitetura - e batizado como Galeria Marianne North (BANDEIRA, 2012). Posteriormente, a coleção totalizou 832 obras (816 pinturas a óleo sobre papel e 16 sobre tela), além de 246 espécies de madeiras coletadas nos países aos quais ela viajou (esta sugestão foi dada a North por Charles Darwin (18091882), com quem se correspondia, segundo Bandeira (2008).). A coleção da flora atlântica brasileira soma 112 obras $(13,46 \%)$ do total iconográfico de North, segundo nossa pesquisa (OLIVEIRA, 2017).

Infere-se que a popularização/divulgação científica da obra de Marianne North só iria se concretizar a posteriori, na musealização de sua pintura e na publicação de sua autobiografia. Nossa tese é de que a especificidade da sua trajetória artístico-científica contribuiu para o alargamento da compreensão da história natural de um período de transição entre os séculos XIX e XX, e também do papel da mulher na arte-ciência. Ela não fazia ilustração científica, nos moldes lineanos. A taxonomia de Carl von Lineu foi desenvolvida no século XVIII, durante a grande expansão da História Natural. Ela classifica os seres em uma hierarquia: reinos, filos, classes, ordens, famílias, gêneros e espécies, além de subdivisões. A ilustração científica nos moldes lineanos deveria seguir este modelo, destacando também partes da planta, com cortes longitudinais e precisão científica. Para mais informações acerca de ilustração científica (CONDURU, R., 2004).

\footnotetext{
${ }^{3}$ Publicado pela primeira vez no período de 1885 a 1901, em 63 volumes. Desde 2004, encontra-se disponível online, pela Oxford University Press.
} 
Marianne estava num campo distinto, sendo elo comunicador e intermediário entre mundos, entre classes sociais, entre tempos, conforme nossas hipóteses.

Deve-se ressaltar que a matriz de ciência, advinda do século XVIII, sofreu forte influência do modelo humboldtiano de matriz romântica, o qual propunha que a multiplicidade de sensações individuais (descrição narrativa e pessoal) e a questão estética (ou seja, a arte) deveriam contar para a descrição da natureza. Alexander von Humboldt (1769-1859) nasceu na Prússia e foi etnólogo, geólogo, mineralogista, botânico, geógrafo, naturalista, entre outros. Considerado o pai da biogeografia, realizou viagens exploratórias ao redor do mundo, não abrindo mão do detalhamento e buscando a visão holística. Para mais informações ver RICOTTA, L., 2003.

A partir de 1859, ano do falecimento de Alexander von Humboldt (1769-1859), e com a publicação do On the Origin of Species by Means of Natural Selection, or the Preservation of Favoured Races in the Struggle for Life, de Charles Darwin, que apresenta os fundamentos da Teoria da Evolução das Espécies por Seleção Natural, conjuntamente à publicação de Alfred Russel Wallace (1823-1913), foram introduzidas nos debates entre os naturalistas (RICOTTA, 2003).

Nossa pesquisa, a partir das fontes consultadas, infere que a produção iconográfica de Marianne North, respaldada por seus escritos nos diários de viagem, os quais trazem o conceito de natureza aplicado aos biomas locais, reflete aspectos das teorias científicas humboldtiana e darwinista a ela coevas. Se, por de um lado, há detalhes realistas e objetivos como a revolução científica pedia, e um enquadramento quase fotográfico e algo moderno; por outro, há uma humanidade subjetiva harmônica no todo, na natureza e nas tonalidades que tomam a tela e explodem em cores vivas, da tinta a óleo. O papel de Marianne North de intermediar o diálogo entre os saberes local e o acadêmico, buscando paisagens em roteiros conhecidos ou inóspitos do império britânico, reforça o que já havia nos avanços da biologia de sua época, conferindo-lhes a materialidade potente de imagens e cores. É o que buscamos comprovar com a pesquisa em curso.

Segundo Ricotta (2003), quando as viagens são assimiladas na sua totalidade, pode se ter como efeito uma estetização do mundo provocada por sua recriação simbólica. O mundo interno se expande, como se imitasse a "majestade" da vegetação, o prazer do belo se intensifica gradativamente, e o isolamento de outrora se ressignifica como transcendência. Com isso, conforme esta autora, a dimensão de totalidade é experimentada nessa intensidade e expansão. Nossa hipótese é de que a coleção de quadros de Marianne North, musealizada em Kew Garden, torna o próprio percurso pelas obras um monumento-estético. Permite ao espectador viajar com Marianne North, conhecer e reconhecer-se como espectador introspectivo, como espectador do outro, e de si no outro. A natureza que se depreende das obras de Marianne North está também relacionada ao conceito humboldtiano e posteriormente darwinista, quando não isola a espécie, e sim a insere no todo, integrando-a e aproximando-a do espectador. É assim, também, uma forma de universalização da ciência.

Adeline Virginia Woolf (1882 -1941) foi escritora, ensaísta e editora britânica, considerada proeminente figura do Modernismo, no século XX, pioneira no uso da narrativa com fluxo da consciência. Conceito advindo da Literatura, fluxo de consciência é uma técnica literária, usada primeiramente por Édouard Dujardin, em 1888, em que se procurava transcrever o 
processo de pensamento de um personagem, com o raciocínio lógico entremeado com impressões pessoais momentâneas e exibindo os processos de associação de ideias. A característica não-linear deste processo de pensamento leva a rupturas na sintaxe e na pontuação. Mostra-se assim, o ponto de vista de um personagem através do exame profundo de seus processos mentais, entre realidade e desejo, entre as lembranças da personagem e a situação presentemente narrada, o que se diferencia de um monólogo (MOISES, 1974).

Assim como North, nasceu em família abastada (South Kensington, Londres), sétima de oito irmãos. Sua mãe, Julia Prinsep Jackson, era modelo dos pintores Pré-rafaelitas (que também influenciaram North) e seu pai, Leslie Stephen, um notável homem das letras (outra similaridade com North, a figura de um pai letrado). Os homens da família receberam educação institucional, enquanto as mulheres foram educadas em casa, com aulas de inglês e literatura vitoriana (assim como North). Sua irmã, Vanessa Bell, destacou-se na pintura modernista. Os irmãos educados em Cambridge e o acesso à vasta biblioteca do pai certamente influenciaram Virginia (HELLER, 2008).

A tia-avó de Woolf, Julia Margaret Cameron, foi amiga e fotógrafa de North, tendo esta descrito com humor a fotografia concebida e tirada, no Ceilão, pela fotógrafa:

Ela me vestiu com cortinas fluidas de lã de caxemira, soltou meus cabelos ... os raios do sol do meio-dia esquivando meus olhos entre as folhas com a leve brisa os moveram, e me disseram para parecer perfeitamente natural (com um termômetro de 96 graus)! Então ela me experimentou com um fundo de folhas e frutas de fruta-pão, pregado contra uma janela e disse-lhes que parecessem naturais, mas ambos falharam. Foi tudo em vão, ela só conseguia encontrar uma pessoa comum perfeitamente desinteressante em seus óculos, à qual recusou-se a lisonjear. (Eden, 119; tradução do original em inglês por R.C. de Oliveira).

Outra referência em comum foi Madge Symonds Vaughan (1869-1925), de quem Marianne North era tia (HELLER, 2008). Madge frequentou a família Woolf e a influenciou, tendo sido inspiração para a personagem Sally Selton em Sra. Dalloway. A infância de Woolf foi marcada por perdas, como a morte abrupta da mãe (em 1895), seguido-se dois anos depois da morte da sua meia-irmã, Stella Duckworth (1869-1897). Tais abalos a acompanhariam durante toda a vida e a levariam ao suicídio. Entre 1897 e 1901, Woolf frequentou o departamento feminino do King's College, no qual estudou os clássicos, história e entrou em contato com o movimento pelo direito das mulheres à educação superior. Encorajada pelo pai, Leslie Stepan (1832- 1904) Woolf começou a escrever profissionalmente em 1900, mas com a morte deste, em 1904, teve nova crise. A família mudou-se, então, para o bairro boêmio Bloomsbury. Foi na conjunção entre os amigos intelectuais dos irmãos e o estilo livre do bairro que se formou o Grupo Bloomsbury. Em 1912, Virginia se casou com Leonard Woolf e o casal fundou a editora Hogarth, em 1917, que publicou a maioria dos seus escritos (HELLER, 2008).

Devido às várias crises e internações, Woolf suicida-se em 1941, com 59 anos de idade. Suas obras foram traduzidas para mais de 50 idiomas e vão desde romances como $A$ viagem $^{6}$ (1915), Sra. Dalloway (1925) e Orlando (1928), entre outros, a ensaios e contos, como Kew Gardens (1919). Além de escritora e editora, Woolf se tornou um tema central para o

\footnotetext{
${ }^{4} 6$ Do original The Voyage out, infere-se contrario sensu pelo título que haveria na concepção da autora uma voyage in, tão presente na obra de Woolf.
} 
movimento crítico feminista dos anos 1970, sendo reconhecida como referência de sua época por Simone de Beauvoir (HELLER, 2008).

\section{Royal Kew Gardens}

Segundo o site do Royal Kew Garden, ele foi criado, em 1759, como um importante centro de estudos, de artes e ciências, que formou coletores botânicos, paisagistas, artistas, os conectando em rede e os colocando em contato com o mundo, em pleno século XIX; esse caráter persiste até hoje. Dirigiram-no Joseph Banks (1743-1820) e William Jackson Hooker (1785-1865), este último de 1841 a 1865. Hooker também presidiu a Royal Society, de 1873 a 1877 e foi colaborador de Charles Darwin, além de Charles Lyell (1797-1875) e de seu filho, Joseph Dalton Hooker (1817-1911), ambos importantes botânicos na Inglaterra do século XIX $7^{5}$. Situado em Londres, no bairro de Kew, os diferentes profissionais que compunham o Royal Kew Gardens organizaram coleções de extensa diversidade vegetal. Marianne North frequentou o Kew Gardens desde cedo, inspirando-se na botânica para viajar o mundo e registrá-la em inúmeras pinturas a óleo. Também foi o local escolhido para que seu legado fosse musealizado. Foi e é, portanto, local de inspiração e memória. Woolf também morou nas cercanias e certamente o frequentou, colocando seu nome como título de um de seus contos.

O conto Kew Gardens escrito por Woolf e lançado em 1919, caracteriza este jardim botânico real como cenário e o eleva também a personagem. Em trechos do conto, a autora aborda aspectos introspectivos e a trajetória do olhar de um personagem humano, de um caramujo ou de uma libélula; apresenta diálogos sobre a memória e sobre pensar o passado. Surgem imagens narradas de pessoas que se dissolvem nas cores do parque, tingidas de cor, vozes sem palavras além de "pétalas de uma infinidade de flores (que) passam suas cores no ar". O local do chá também é um ponto de inflexão, uma vez que apresenta nele tanto o costume inglês quanto a possibilidade de haver um local deste tipo no Kew Gardens (WOOLF, 1989). Marianne North, no século anterior, já havia proposto ao diretor do Kew uma casa de chá e café, por ocasião da inauguração da galeria que leva seu nome, o que lhe foi negado pelo Departamento de Alimentação do governo local (BANDEIRA,2012). North, então, pintou nos portais da galeria, flores de chá e de café (Idem, Ibidem). Neste aspecto, é como se Virginia conversasse e respondesse à Marianne: “- Aquela sua ideia é possível hoje!”

Segundo Heller (2008), em Entre os Atos (Between the Acts), último romance de Virginia Woolf, publicado em 1941, o personagem Sr. Cobbet encontra-se embaixo de uma árvore, a Monkey Puzzle Tree. Tal espécie também fora apresentada por Marianne North tanto na publicação Eden (composta por trechos de seus diários de viagem) quanto nas suas telas chilenas. Ainda segundo Heller, utilizar a Monkey Puzzle Tree como cenário já é indício de alguma relação entre as obras de North e Woolf; sabe-se também que Woolf nunca viajou ao Chile (CARVALHO, 2018), onde estas espécies são comuns. Para Heller, na descrição da Araucaria araucana ou Monkey Puzzle Tree, de North há certa dose de humanismo, a caracterizando quase como uma pessoa, uma companhia. Vejamos a descrição de North, a seguir:

\footnotetext{
5 Em 2003, o Kew Gardens foi incluído na lista de patrimônio mundial da UNESCO. Disponível em: http://whc.unesco.org/en/list/1084. Acessado em: 12/11/17.
} 
“... nenhuma das árvores com mais de trinta metros de altura ou seis metros de circunferência, e é estranho dizer que, elas pareciam todas muito velhas e muito jovens. Não vi nenhum daqueles espécimes nobres de meia-idade nos parques ingleses que temos, com galhos mais baixos repousando no chão. ... Os cones menores das árvores masculinas estavam sacudindo nuvens de pólen dourado e cheios de pequenas larvas; estes atraíram vôos de periquitos verdes bronzeados, que estavam muito ocupados com eles... mais notável é a casca, que é um quebra-cabeça infantil perfeito de peças de tamanhos diferentes, com cinco ou seis lados distintos cada, todos combinados com a arrumação de um de um favo de mel.... (eles) têm corpo de ovelha e cabeça de camelo." (Tradução desta autora $)^{6}$

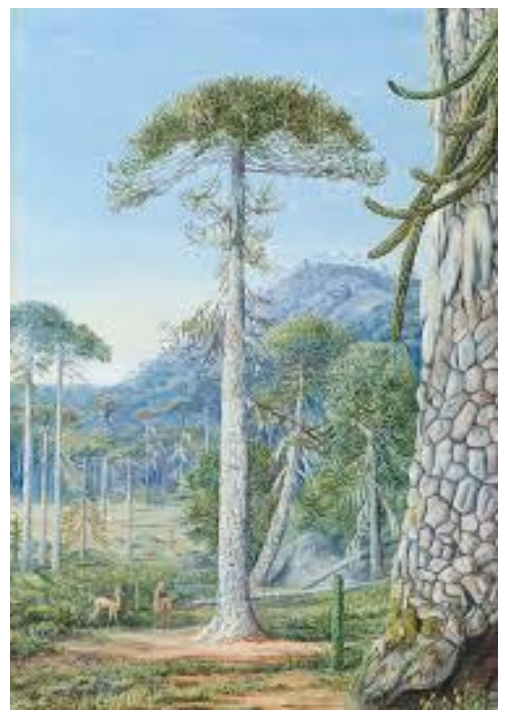

Figura 1. NORTH, Marianne. Monkey Puzzle Tree and guanacos, Chile, 1884. ${ }^{7}$

Já em Virginia Woolf, na obra Entre os Atos (Between the Acts), a autora ambienta um personagem Sr. Cobbet, embaixo da tal árvore, pensando no comportamento de outra personagem (Miss La Trobe).

(Cobbet) sozinho embaixo da Monkey Puzzle Tree, rosa, e murmura. O que a (Srta. La Trobe) fez ter antiguidade com esse glamour,- essa farsa, e a faz subir, subir na Monkey Puzzle Tree? Cobbet no canto viu através de seu

\footnotetext{
6 "I saw none of the trees over one hundred feet in height or twenty feet in circumference, and strange to say, they seemed all very old and very young. I saw none of those noble specimens of middle age we have in some English parks with lower branches resting on the ground....The smaller cones of the male trees were shaking off clouds of golden pollen, and full of small grubs; these attracted flights of bronzy green parakeets, which were very busy over them. The most remarkable thing is its bark, which is a perfect child's puzzle of slabs of different sizes, with five or six distinct sides each, all fitted together with the neatness of a honeycomb.... (they) have body of a sheep and the head of camel" (Eden, p. 228-229)

${ }^{7}$ Disponível em: https://www.kew.org/mng/gallery/004.html. Acessado em: 12/12/2019.
} 


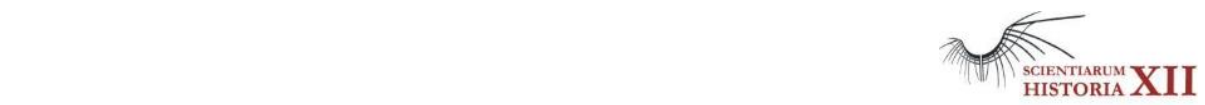

joguinho. Ele conhecia a natureza humana no Oriente. Foi o mesmo no leste. Foi o mesmo no oeste. As plantas permaneceram." (tradução desta autora) ${ }^{8}$

Infere-se que as obras de North e Woolf conversam entre si. Woolf nunca viajou ao Chile e tal espécie ainda não havia sido plantada no Royal Kew Gardens. Woolf também se questionava como as pessoas viam as cores por acreditar que se viam as mesmas de forma diferente. Também fala do olhar das crianças, cita a cegueira dos políticos e dos homens de negócios; e sobre o olho de um inseto, diz que de tão desenvolvido teria se tornado uma infinidade em olhos (HELLER, 2008).

\section{Conclusões}

Esta pesquisa sugere que tenha havido influência direta da obra oitocentista de Marianne North (1830-1890) sobre a escrita literária de Virginia Woolf (1882-1941). Ambas romperam com estruturas tradicionais que constrangiam a liberdade das mulheres, cada uma a seu modo. O rompimento de Marianne North com a estrutura vitoriana para as mulheres foi uma contínua viagem "para fora", para o mundo. Encontrou aí uma maneira de controlar a própria vida e de, posteriormente, deixar memória de sua plasticidade e das qualidades de seu pensamento cognitivo pré-linguístico através de das telas, tão admiráveis, e que testemunham, explicitamente, as bases de criação em qualquer campo de conhecimento, sobretudo quando considerados os processos de construção em arte e em ciência.

Sua produção foi doada à nação (à coroa inglesa) por meio da musealização da mesma em Kew. A especificidade da sua trajetória artístico-científica contribui para compreensão dos avanços no conhecimento da história natural no período de transição entre os séculos XIX e $\mathrm{XX}$, e do papel da mulher nesse processo, que hoje poderíamos classificar como genuinamente artsci (FRÓES, 2015). Marianne estava seu tempo e flertava com tempo vindouro.

Pode-se inferir que, enquanto Marianne North encontrava, nas viagens para o mundo (para fora), uma saída para o luto e para o controle sobre sua própria existência, num mundo masculino e vitoriano, Virginia Woolf fazia suas viagens para dentro, para o fluxo de consciência, para a subjetividade, para a literatura. Curioso notar que o primeiro romance de Virginia Woolf se intitula The Voyage Out.

Especialistas consideram as cores uma característica importante na obra de Virginia Woolf. Certamente, esta teve acesso à Galeria Marianne North, cujas obras pictóricas e narrativas contribuíram para o estilo criativo de Woolf. A experiência explosiva que, ao que se sugere, Woolf teria vivenciado com as cores na obra de North parece ter se transduzido, em Woolf, como narrativa plena em afeto e subjetividade. A percepção, descrição e associação evidente nas cores referenciadas em North, foi aprofundada com o fluxo de sensibilidade narrativa de Woolf. O Kew Gardens as aproximou e as singularizou, na trajetória interna de uma, e nas

\footnotetext{
${ }^{8}$ Heller apud Woolf: "Alone under the monkey puzzle tree, rose and mutteres. What made her indue the antique with this glamour, this sham lur, and set em climbing climbing up the tree. Cobbet in his corner saw through her little game. He had known human nature in the East. It was the same in East. It was the same in West. Plants remained - the carnation, the zinnia and the geranium..."
} 
viagens pelo mundo da outra. A delicada combinação de razão e emoção, arte e ciência, reconhecida em Marianne North, vive em Virginia Woolf.

\section{Financiamento}

O presente trabalho foi realizado com apoio da Coordenação de Aperfeiçoamento de Pessoal de Nível Superior - Brasil (CAPES) - Código de Financiamento 001.

\section{Referências}

BANDEIRA, J. A viagem de Marianne North ao Brasil (1872 - 1873). Rio de Janeiro: Sextante, 2012.

CARVALHO, J. V. (Seleção, tradução, introdução e notas). Viagens - Virginia Woolf. Lisboa: Relógio D’Água Editores, 2018.

CONDURU, R. 'Nas frestas entre a ciência e a arte: uma série de ilustrações de barbeiros do Instituto Oswaldo Cruz'. História, Ciências, Saúde - Manguinhos, vol. 11(2): 335-84, maio-ago. 2004.

DESCARTES, R. Discurso do Método. Introdução, análise e notas de Étienne Gilson. São Paulo: Martins Fontes, 2007.

HELLER, H. The Botanical Works of Marianne North (painter, writer, traveler), edited by absortion into Virginia Woolf's writting. In: Conferência Anual sobre Virginia Woolf, Universidade de Colorado (Estados Unidos), 2008.

FRÓES, M. M. An artsci science. Technoetic Arts, v. 13, 2015, p. 203-217.

. Hiperfaces do híbrido arte-ciência: bio-grafos de uma anatomia da paixão humana. In: NÓBREGA, A. M. e FRAGOSO, M. L. P. G. (Orgs.). Hiperorgânicos: ressonâncias, arte, hibridização e biotelemática. Rio de Janeiro: Rio Book’s, 2016, p. 144-181.

. O Sonho de Descartes. In: SCIENTIARUM HISTÓRIA, 3, 2010, Rio de Janeiro. Livro de anais do Scientiarum História III, Rio de Janeiro: UFRJ, 2010. Disponível em: http://www.hcte.ufrj.br/index.html?arq=scientiarum.htm\&flag=expand. Acesso em: 3 nov. 2019.

MARTINELLI, G.; MORAES, M.A. (Orgs.). Livro Vermelho da Flora do Brasil. Rio de Janeiro. Rio de Janeiro: Andrea Jacobson/Instituto de Pesquisas do Jardim Botânico do Rio de Janeiro, 2013. 1100 p.

MOISES, M. Dicionário de Termos Literários. São Paulo, Cultrix, 1974.

NORTH, M. Recollections of a Happy Life: Being the Autobiography of Marianne North, edited by Mrs. John Addington Symonds, 2 volumes, originally by published Macmillan and Co, London, 1894. Forgotten Books, 2012. 

1980.

. A Vision of Eden. The life and Work of Marianne North. Exeter: WEBB\&Bower, Official Guide to the Marianne North Gallery. Royal Botanical Gardens, Kew, 2009.

OLIVEIRA, R.C. Marianne North: uma caçadora de paisagens na mata atlântica brasileira (1872-1873). In: Livros dos Anais Scientiarum Historia X: Filosofia, Ciências e Artes. Rio de Janeiro: UFRJ/HCTE, 2017.

ORDINE, N.. A utilidade do inútil: um manifesto. Rio de Janeiro: Zahar, 2013.

RICOTTA, L. Natureza, Ciência e Estética em Alexander Von Humboldt. Rio de Janeiro: MAUAD, 2003.

WOOLF, V. Kew Gardens. In: Complete shorter fiction of Virginia Woolf. 2a ed. New York: Harcourt Brace, 1989. . Between the Acts. London: Hogarth Press, 1941. 